\title{
EDITORIAL
}

\section{Pharmacy, the interdisciplinary field of science}

\author{
Editor-in-Chief: Professor Pál Perjési
}

Pharmacy is an interdisciplinary field of science, which covers the knowledge of fate of drugs (pharmacons), excipients and formulated pharmaceutical products outside and inside the body. Separation of pharmacy as a separate entity of medicine is dated back to the ninth century. ${ }^{[1]}$ The trend toward specialization was later reinforced by a law enacted by the German Emperor Frederic II at the beginning of the thirteenth century. ${ }^{[2]}$ Since these early times pharmacy underwent a continuous and intense development. Pharmaceutics, Pharmaceutical chemistry, Pharmacognosy, Pharmacology and Toxicology are the conventional fields of pharmacy, which serve as the source of practical and theoretical basis of development of new pharmaceutical products.

Pharmaceutical research covers synthesis, isolation and standardization of drugs, studies on physico-chemical basis of pharmaceutical formulations and controlling quality of the drugs and their different dosage forms. Those substances that are made from a living organism are called biological drugs. Since the physico-chemical properties of these latter drugs are rather different from the synthetic or isolated small molecules, manufacturing, quality control and formulation of them need new techniques and protocols. The accumulated knowledge of these disciplines is referred to as Pharmaceutical Biotechnology. ${ }^{[3]}$

Received: July 8, 2018; Accepted: July 8, 2018; Published: July 10, 2018

Correspondence to: Pál Perjési, Institute of Pharmaceutical Chemistry, University of Pécs, Pécs, Hungary; Email: pal.perjesi@ aok.pte.hu

Citation: Perjési P. Pharmacy, the interdisciplinary field of science. J Pharm Biopharm Res, 2018, 1(1):1-2

Copyright: (c) 2018 Pál Perjési.This is an open access article distributed under the terms of the Creative Commons Attribution License, which permits unrestricted use, distribution, and reproduction in any medium, provided the original author and source are credited.
Another branch of pharmaceutical research is the availability to the body (bioavailability) of the various dosage forms of drugs. Biopharmacy examines the interrelationship of the physi$\mathrm{cal} / \mathrm{chemical}$ properties (SAR/QSAR) of the drug, the dosage form in which the drug is given, and the route of administration on the rate and extent of systemic drug absorption. Pharmacokinetics, physico-chemical characterization, biotransformation (metabolism) and interactions of drugs are the main disciplines of biopharmaceutical research. ${ }^{[4]}$ Since analysis of drugs and drug metabolites in biological samples needs complex sample preparations as well as selective and sensitive analytical methods, a new subdiscipline of Pharmaceutical analysis, Bioanalysis, has been emerged to meet the scientific needs and regulatory requirements.

The Journal of Pharmaceutical and Biopharmaceutical Research (JPBR) is an international peer reviewed open access journal from SyncSci Publishing Group. The journal is intended to provide scientists, researchers and students worldwide with unlimited access to the latest advances of the pharmaceutical and biopharmaceutical sciences. It is, therefore, an honor for me and a great privilege to lead this new journal.

JPBR publishes Original research works, Reviews and Short communications in the entire spectra of pharmaceutical research briefly summarized above. It will also accept (a) Abstracts and Proceedings of scientific meetings relevant to the journal, following consideration and approval by the Editorial Board; (b) Announcements of meetings related to the fields of the journal and 
(c) Short reviews (of approximately 120 words) and announcements of newly received books related to the fields of the journal.

I would like to express my appreciation to the members of SyncSci Publishing Pte Ltd for founding this new forum of pharmaceutical research and to each colleague all over the world who decide to contribute their submissions to the success of this journal of pharmaceutical sciences.

\section{References}

[1] Al-Gazal SK. The valuable contribution of Al-Razi (Razes) in the history of pharmacy during the Mid- dle Ages. J Int Soc Hist Isl Med. 2004, 3(6):9-11.

[2] Sonnedecker G. Rev. Kremers and Urdang's History of Pharmacy, 4th ed; Am Inst Hist Pharm, Madison, WI, USA, 1986, p 34.

[3] Walsh G. Pharmaceutical Biotechnology Concepts and Applications; Wiley, Chichester, West Sussex, UK, 2007.

[4] Sugano K. Biopharmaceutics modeling and simulations: Theory, practice, methods, and applications. John Wiley \& Sons, Hoboken, New Jersey, USA, 2012. 